\title{
Ecological Site Descriptions: Consideration for Riparian Systems
}

\section{By Tamzen K. Stringham and Jeffery P. Repp}

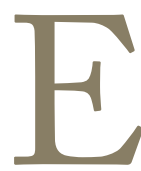
cological sites, and the previous iteration known as range sites, have provided ecologically based guidance in making land management decisions for more than 60 years. ${ }^{1}$ However, previous site description approaches failed to sufficiently describe the specific functions and processes unique to riparian areas, subunits critical to landscape function. Riparian areas are defined as the transition zone between the uplands where there is seldom standing water and the stream, lake, or spring where free-flowing or standing water supports a suite of water-loving plants such as sedges, rushes, and willows. ${ }^{2}$ Riparian zones in the western United States occupy only a small proportion of the total landscape and are often narrow corridors associated with streams. In spite of this limited area, about $80 \%$ of the terrestrial wildlife species known to occur in southeastern Oregon, for example, are dependent on these ecosystems for some portion of their life cycle. ${ }^{3}$ Riparian zones and meadows have also been found to provide a high proportion of summer forage for livestock and big game. ${ }^{2}$ The importance of riparian areas to wildlife, livestock, fisheries, and water quality is well recognized, but the development of riparian ecological sites and the associated state-and-transition models (STMs) is a recent phenomenon.

\section{How Are Riparian Ecological Sites Different From Upland Sites?}

An ecological site is the product of soils, topography, climate, and natural disturbances. The combination of specific environmental factors generates unique plant communities that typically repeat across the landscape. ${ }^{1}$ An ecological site is recognized and described on the basis of these environmental factors and the associated characteristic plant community. On upland areas, site characteristics such as climate, landscape position, and soil features remain relatively stable over time; however, in riparian ecosystems there is often a continual process of change driven primarily by hydrologic forces. Even under "natural conditions," riparian plant communities can be quite variable. ${ }^{4}$ Riparian areas have several unique properties compared to uplands that require modifications to the accepted protocols for ecological site delineation and description. Current efforts to do so are focused on riparian areas associated with stream systems (lotic riparian areas), and those systems will be the focus of this paper.

\section{How Do Landform and Stream Type Influence Riparian Vegetation?}

Understanding the geomorphology (landform) of riparian systems is integral to defining riparian vegetation potential, predicting dynamics, and understanding the physical distribution and extent of the complex of vegetation community types found in a valley. Valley types as defined by Rosgen ${ }^{5}$ are characterized by the shape, gradient, width, side-slope gradient, and aspect of the landform. Fluvial surfaces (water flow features) within stream valleys feature particular soil and hydrological characteristics (soil texture, soil moisture, depth to water table, flooding regime, etc.) that influence the development of plant communities. ${ }^{6}$

Fluvial surfaces are formed by streams through the process of sediment movement and deposition. Crowe and Clausnitzer ${ }^{6}$ identified the distinct plant communities associated with the following fluvial surfaces: alluvial bars, stream banks, floodplains, overflow channels, and terraces. They recognized that in some riparian settings the fluvial surfaces are less well-defined and gradients of soil and hydrological features are associated with changes in plant communities (Fig. 1). Depending on the valley type and the stream channel hydrology, multiple fluvial surfaces may occur within the basin leading to a multitude of plant community types created by specific channel-soil-groundwater relationships. Valley type or landform is strongly coupled to the associated stream channel.

Leopold et al. ${ }^{7}$ indicated that streams have repeating characteristics such as gradient, sinuosity (pattern), width: 


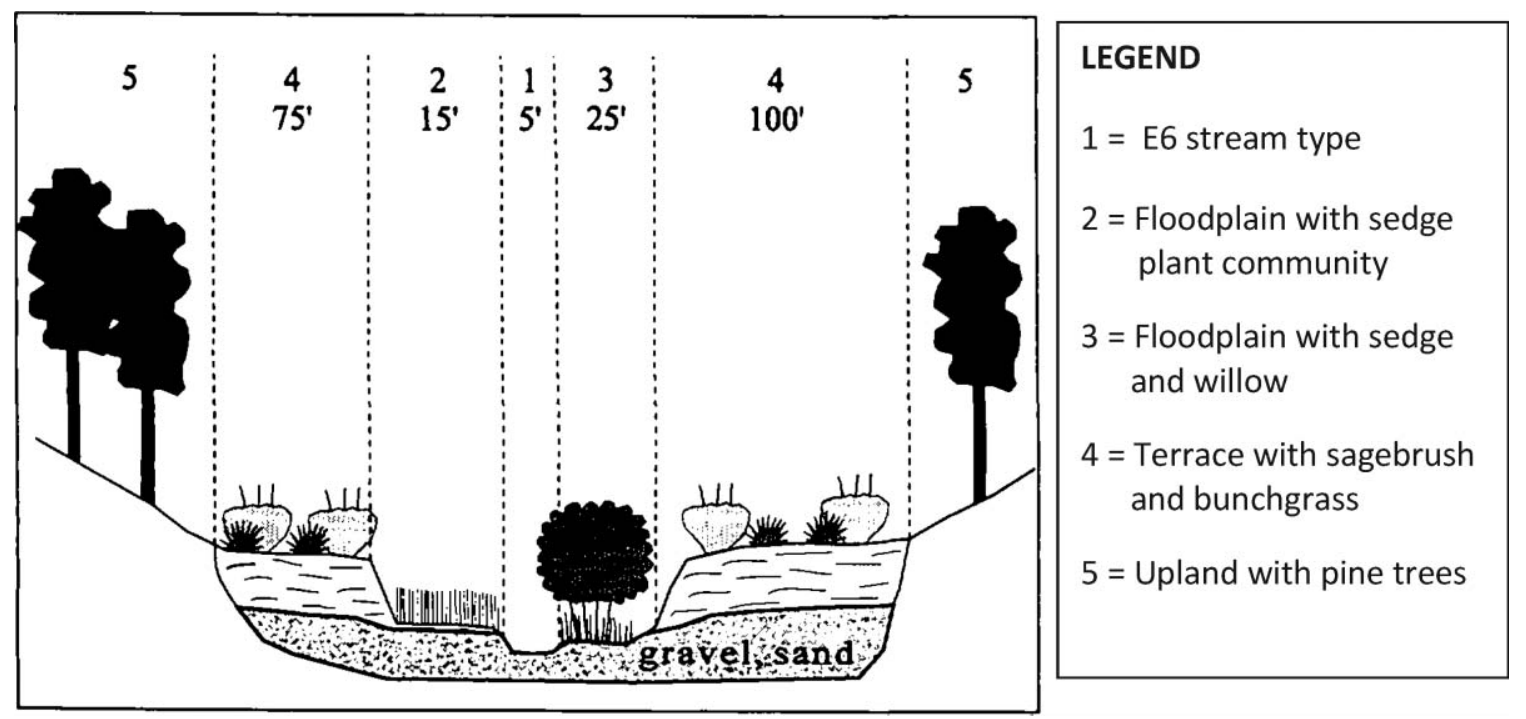

Figure 1. Fluvial surfaces with associated riparian plant communities. Modified from Crowe and Clausnitzer. ${ }^{6}$

depth ratio, entrenchment ratio, channel materials, and confinement that are developed through the relationship with the surrounding landform (valley type). Rosgen ${ }^{5}$ enhanced these concepts into a stream classification system based on both valley type and channel characteristics: dimension (width-depth), pattern (sinuosity), and profile (slope).

Winward ${ }^{4}$ recognized the importance of combining valley types and channel types into a cohesive unit for the purpose of describing, inventorying, and managing riparian ecosystems. He proposed a land unit type titled a riparian complex identified by overall geomorphology (valley type), stream gradient, substrates, and associated water flow features (fluvial surfaces) along with general vegetation patterns (Fig. 2). He suggested that each riparian complex is usually composed of a mix of multiple plant communities created through the hydrologic coupling of the stream channel with the associated riparian area. The hydrologic linkage between channel morphology and adjacent stream-dependent meadows or riparian areas indicates that

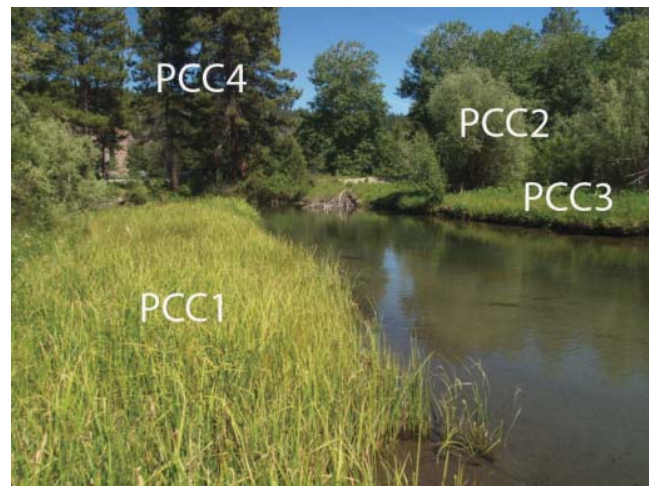

Figure 2. Riparian ecological site with four plant community components (PCC) associated with different fluvial surfaces. Stream type is an E6 located in a Valley Type $X^{5}$ a change in channel characteristics and/or fluvial surfaces will likely result in a change in the vegetation of the associated riparian areas. Winward ${ }^{4}$ suggested that a common characteristic of the vegetation within a riparian complex involves the gradual movement of plant community types within the complex as stream channels move naturally across the valley.

Less commonly, long-term, self-perpetuating plant communities can develop on very low-gradient $(\leq 1 \%)$ stream channels or where channels are armored with bedrock or large cobbles and boulders. The gradual movement of plant community types within riparian ecosystems suggests that the ecological site concepts utilized to describe them must be modified from those used in upland ecosystems where inherent (use-independent) soil properties change more slowly.

\section{Describing the Riparian Complex Ecological Site}

We propose coupling the riparian complex and valley type/ stream channel classifications to adapt ecological site concepts to the characteristics of riparian areas. Stringham et al. ${ }^{8}$ suggested the following definition for riparian complex ecological sites: "A geomorphic unit consisting of a valley type and stream type with a specific set of physical characteristics that differ from other kinds of land and in its potential to produce a distinctive riparian complex defined by a characteristic and interacting mosaic of biotic communities." This proposed definition incorporates a number of important changes from the Natural Resources Conservation Service definition for ecological sites. First, it recognizes the importance of hydrology in the development of associated plant communities through incorporation of valley types, channel morphology and substrates, flood characteristics, fluvial surfaces, groundwater, and soils in the development 
and maintenance of riparian vegetation. Ecological sites currently focus first on climate, landform, and soils as the primary drivers in plant community development with hydrology as a secondary component. Secondly, the definition embraces the idea that multiple plant community types can be described in one ecological site. Finally the definition specifies that plant communities can be mobile within the physical boundaries of the riparian ecological site. Guidelines for upland ecological sites do not accommodate more than one plant community per ecological site nor do they recognize the mobility of plant communities within the boundaries of an ecological site. To reduce confusion with regard to the "characteristic" or "reference" plant community phase, Stringham et al. ${ }^{8}$ proposed naming the individual vegetative units contained within the mosaic of biotic communities "plant community components." As such, the plant community components are defined as an assemblage of plant species that represent the structure and composition of community phases with no indication of successional status. They occur as patches, stringers, or islands, and are distinguished by floristic similarities in both overstory and understory layers. ${ }^{8}$ In a riparian complex ecological site, the concept of a characteristic or reference plant community contains a description of multiple plant community components along with their spatial distribution within the physical boundaries of the site (Fig. 2).

We propose that riparian ecological site descriptions include explicit identification of geomorphology (valley type, stream channel type, and substrates) and vegetation (greenline [or channel edge] and valley cross-section estimates of vegetation composition by species), including production within each of the riparian plant community components. In addition to standard soil descriptions, estimates of depth to water table and depth to redoximorphic features within each plant community component are strongly recommended.

\section{STMs Designed for Management}

A critical step in the development of an ecological site description is the STM. The STM is used to describe vegetation and soil response to various disturbances. It identifies the different soil-vegetation states and plant community phases within states that may exist on an ecological site, describes the changes in ecological processes that cause vegetation change, and, finally, depicts the processes necessary to restore plant communities to a desired state. The STM concepts for upland ecosystems are well developed with respect to plant community change within a state (community pathways). Community pathways are typically driven by fire, grazing, drought, or some combination of the three. Transitions leading to new stable states are typically due to invasive plant encroachment and soil quality change or erosion. In order to develop STMs for riverine riparian ecosystems, the drivers of community pathways and transitions must include hydrologic processes.

\section{Understanding Stream Dynamics and Disturbance Response}

The natural range of variability for a stream channel is defined by climate, geomorphology (valley type, channel type), and their interaction with vegetation. This is described via the reference state in the ecological site description. Disturbances can lead to accelerated bank erosion, accelerated sediment supply, or changes in stream flow. These changes can cause channel instability leading to channel incision (down-cutting) or widening. ${ }^{9}$ Stream channel evolution or succession models provide a tool for understanding the channel dimension, pattern, and profile changes that can occur as a result of disturbance. Incisement or widening of stream channels often causes a decoupling of the channel hydrology from the associated riparian area through reduced access of flood waters to floodplains leading to reduced soil-water and groundwater recharge. The reduction in available soil water for vegetation can cause shifts in plant composition from water-loving plants to plants more typically found in upland ecosystems.

An example of the process of channel incision is presented in a series of photographs (Fig. 3). A stream channel, classified as Rosgen E6 (slightly entrenched, very low width: depth ratio, high sinuosity, silt and clay bed materials) is tightly connected to the floodplain and surrounding riparian area (Photo 1). The vegetation on the greenline is composed of sedges and rushes, both species needing water in the rooting zone during the entire duration of the growing season. These species stabilize the stream channel banks with their roots. Willows and aspen can be seen in the background where depth to groundwater may be deeper than at the edge of the stream channel. The stream supports the groundwater levels in the meadow, thereby supporting these additional riparian plant community components. Photo 2 depicts the same stream channel in a different location within the same valley. Channel incision (bed lowering) has begun as evidenced by the change from dominance of sedge plants on the greenline (vegetation nearest the channel edge) to pockets of sedges with a dominance of Kentucky bluegrass and other plant species that do not tolerate saturated soil in the rooting zone for the entire growing season. The stream is still able to access the floodplain during high-flow events, but the meadow water table has lowered slightly as revealed by the dominance of non-water-loving plants. Grazing management alone may prevent this stream from evolving to that depicted in Photo 3. Photo 3 represents severe channel incisement and disconnection from the surrounding floodplain. Stream bank vegetation is composed primarily of Kentucky bluegrass and forbs that are unable to stabilize stream banks during high-flow events. Banks are actively eroding and channel instability is high. Photo 4 depicts a Rosgen E6 stream that has completed the channel evolution process of incisement and has reestablished stability and connectedness to the associated floodplain. Stream bank vegetation along with 

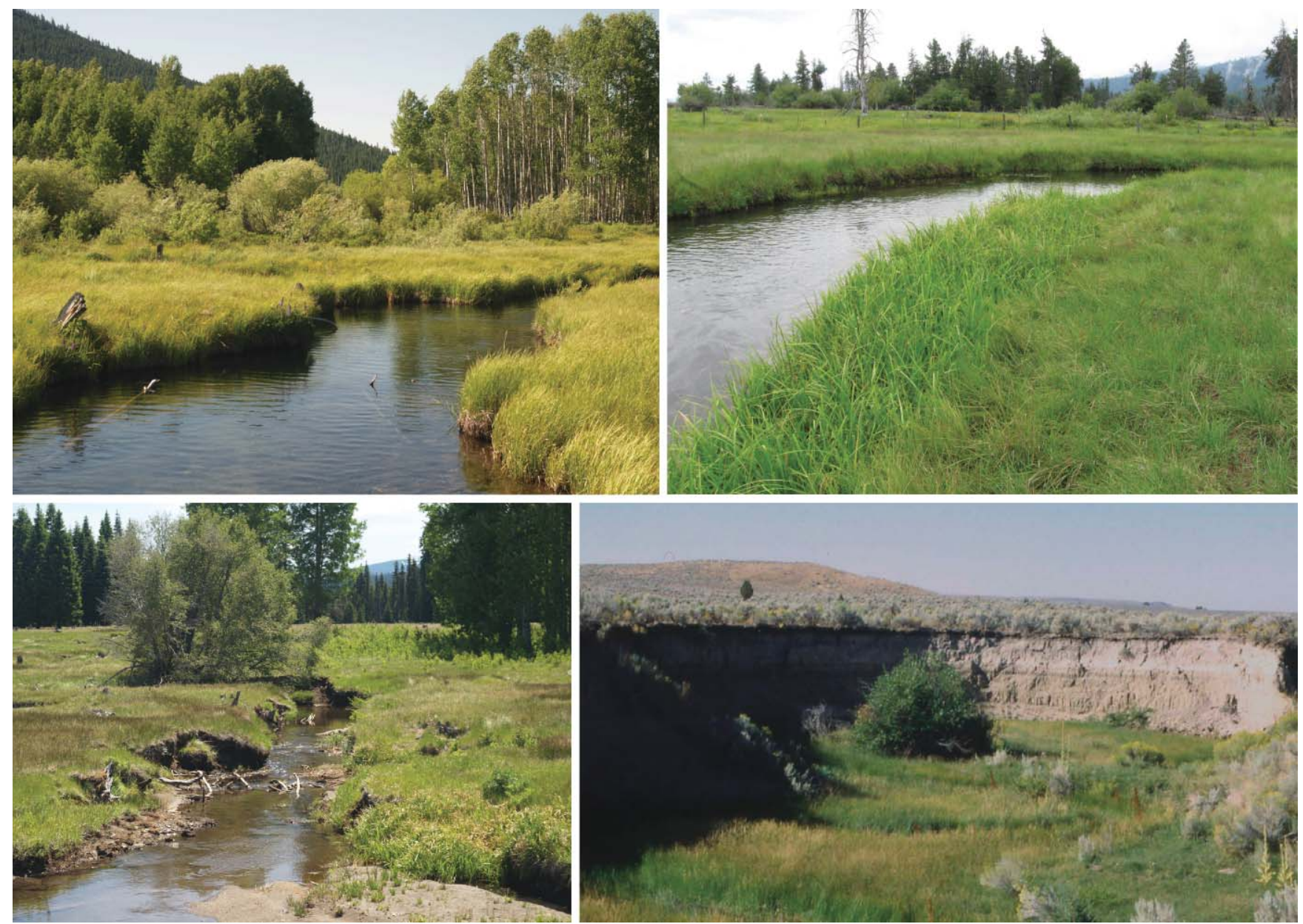

Figure 3. Photo depiction of the channel evolution model (photo 1 top left, photo 2 top right, photo 3 bottom left, photo 4 bottom right).

the riparian area exhibit a plant community composed of water-loving plants. However, the incisement of the stream to a much lower base level has greatly reduced the historical extent of the riparian area and the water holding capacity of the basin.

\section{Developing the Riparian STM}

Riparian STMs can be developed by combining the experiential and observational knowledge contained within stream classification, channel evolution models, and riparian vegetation-soil-water relationships. These models are excellent tools for describing how disturbances impact vegetation and channel stability, allowing managers to make informed decisions on methods for improving riparian area function.

We propose expanding the concepts for development of STMs in upland areas to better describe riparian areas. The expansion of concepts should include channel classification, identification of fluvial landforms, channel evolution models, multiple riparian plant community components per plant community phase, and knowledge of soil-water-vegetation dynamics focused strongly on water table and channel dimension relationships (Fig. 4).

The STM diagram and narrative portion discusses community phases and pathways describing plant community dynamics (phase changes) within states, disturbances resulting in changes to a new state (transitions), and restoration pathways. For example, in the draft model presented in Figure 4 , community pathway $1.1 \mathrm{~A}$ describes a large flood event resulting in willow damage, sediment deposition, and expansion of the sedge-rush community component. Community pathway $1.2 \mathrm{~B}$ is potentially caused by inappropriate grazing leading to dominance by Kentucky bluegrass. The transition and threshold between state 1 and state 2 is described in T1A and is driven by hydrologic modification of the stream channel (incision or widening) leading to a reduction or elimination of the sedge-rush component in favor of Kentucky bluegrass and rush species. The transition (T2A) between state 2 and state 3 is characterized by further stream incision followed by channel stabilization and reestablishment of a connection with the new, smaller riparian area. The restoration pathway (R3A) leading from state 3 to state 1 would require filling, diking, damming, or other modification of the incised and widened channel to bring meadow water table levels back to state 1 levels.

To visually illustrate the states and community phases within the draft STM (Fig. 4), the photos presented in Figure 3 may be linked to the box-and-arrow diagram as follows: Photo 1 depicts community phase 1.1 and Photo 2, 


\section{Riparian Complex Site, E6 (silt/clay) Stream Type}

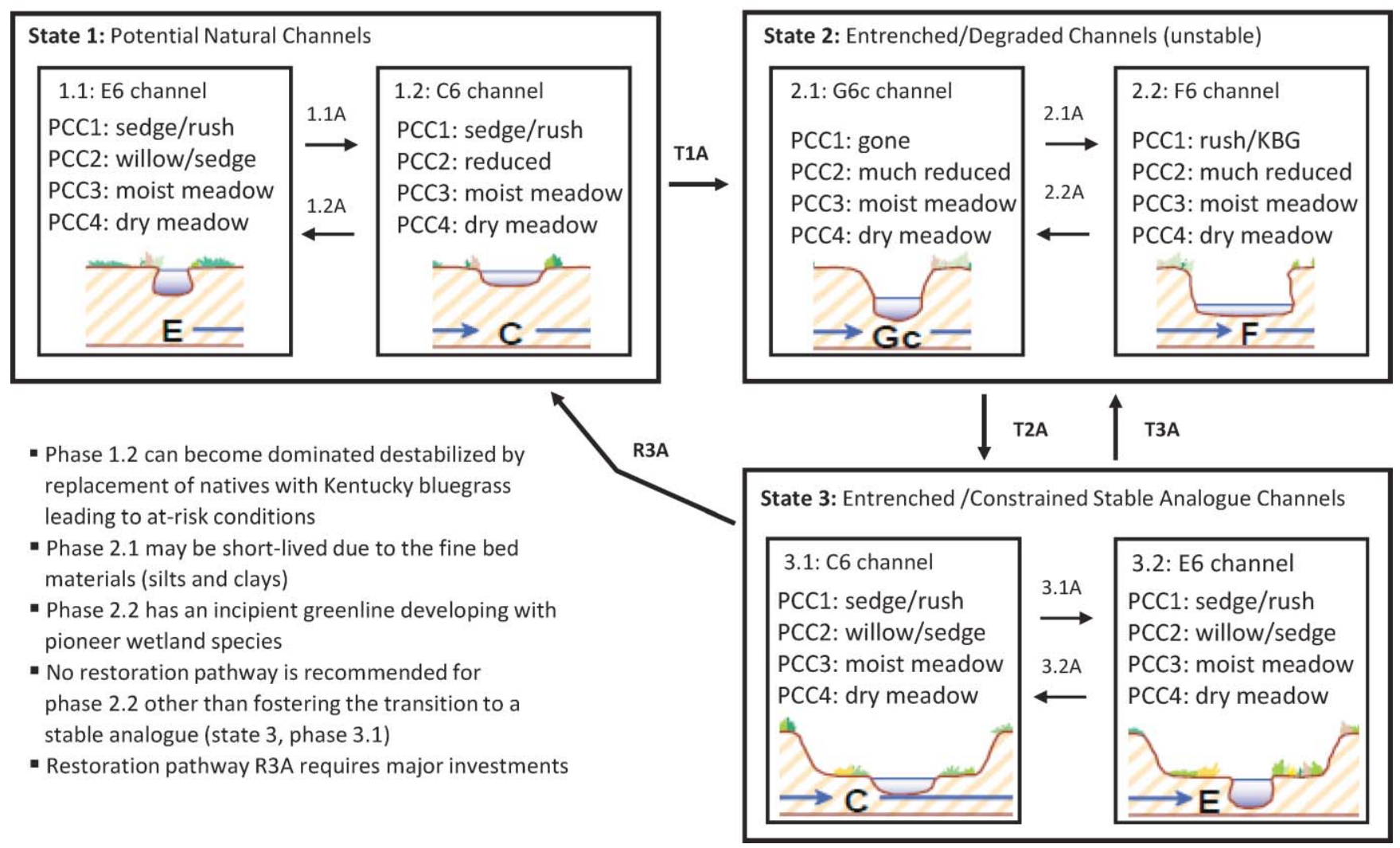

Figure 4. Riparian-complex ecological site draft state-and-transition model. State 1 is composed of two plant community phases with multiple riparian plant community components (PCC). Numbering of components corresponds with the order of spatial distribution and occurrence from the edge of the stream channel. Plant community pathways are indicated by numbered directional arrows between community phases. Transitions across thresholds from one state to another are indicated by directional arrows with a label beginning with capital $\mathrm{T}$. Restoration pathways are labeled with directional arrows with a label beginning with capital $\mathrm{R}$.

community phase 1.3 within state 1 ; Photo 3 represents community phase 2.1 in state 2 ; and Photo 4 , community phase 3.1 in state 3 .

\section{Summary}

Riparian areas provide multiple ecosystem services, including high-quality summer forage for big game and livestock, flood attenuation, groundwater recharge, and wildlife habitat. The development of riparian ecological site descriptions has evolved relatively recently and focuses on riverine riparian systems. Ecological site description formats based on upland rangeland concepts and theory do not adequately represent the key biophysical properties of riparian-complex ecological sites including geomorphology (valley type), stream gradient, substrates, associated water flow features (fluvial surfaces), and plat community patterns. Development of riparian ecological site descriptions is a necessary expansion of concepts and approaches used to describe upland areas. Descriptions of plant community dynamics and thresholds associated with and/or resulting from hydrologic processes are a primary consideration when developing STMs for riverine riparian ecosystems. In this paper, we provide concepts and a rationale for the development of STMs for these systems. STMs can include channel classification, identification of fluvial landforms, channel evolution models, multiple riparian plant community components per plant community phase, and soil-water-vegetation dynamics with strong emphasis on water table and channel dimension relationships. The riparian STM presented in this paper provides a template for combining current understanding of stream dynamics with ecological principles in a management context. Riparian ecological site descriptions and STMs will refine and enhance the way we categorize, map, and manage these important ecosystems.

\section{References}

1. Boltz, S., and G. Peacock. 2002. Ecological sites: understanding the landscape. Rangelands 24:18-21.

2. Svejcar, T. 1997. Riparian zones: 1) what are they and how do they work? Rangelands 19:4-7.

3. Thomas, J. W., C. Maser, and J. E. Rodierk. 1979. Wildlife habitats in managed rangelands - the Great Basin of southeastern Oregon: riparian zones. Portland, OR, USA: US Department of Agriculture, Forest Service, Pacific Northwest Region. GTR PNW-80. 17 p.

4. Winward, A. H. 2000. Monitoring the vegetation resources in riparian areas. Ogden, UT, USA: US Department of 
Agriculture, Forest Service, Rocky Mountain Research Station. Gen. Tech. Rep. RMRS-GTR-47. 49 p.

5. Rosgen, D. 1996. Applied river morphology. Pagosa Springs, CO, USA: Wildland Hydrology. 364 p.

6. Crowe, E. A., and R. R. Clausnitzer. 1997. Mid-montane wetland plant associations of the Malheur, Umatilla and Wallowa-Whitman national forests. Portland, OR, USA: US Department of Agriculture, Forest Service, Pacific Northwest Region. Technical Paper R6-NR-ECOL-TP-22-97. 299 p.

7. Leopold, L. B., M. G. Wolman, and J. P. Miller. 1964. Fluvial processes in geomorphology. San Francisco, CA, USA: Freeman. 522 p.

8. Stringham, T. K., J. P. Repp, P. Novak-Echenique, B. Southerland, and B. Gillaspie. 2008. Riparian ecological site description and state-and-transition modeling workshop, part II; 18-20 November 2008. Reno, NV, USA: University of Nevada, Reno.

9. Rosgen, D. 2006. Watershed assessment of river stability and sediment supply. Altona, Manitoba, Canada: Friesens Printing. $628 \mathrm{p}$.

Authors are Associate Professor, Department of Animal Biotechnology, University of Nevada, Reno, Reno, NV 89557, USA, tstringham@cabnr.unr.edu (Stringham); and Rangeland Management Specialist, USDA-Natural Resources Conservation Service, West National Technology Support Center, Portland, OR 97232, USA (Repp). 